\title{
Optical and Structural Investigation of CdSe Quantum Dots Dispersed in PVA Matrix and Photovoltaic Applications
}

\author{
Pallabi Phukan and Dulen Saikia \\ Material Science Laboratory, Department of Physics, Sibsagar College, Joysagar, Assam 785665, India \\ Correspondence should be addressed to Dulen Saikia; dulen.s@rediffmail.com
}

Received 30 May 2013; Revised 21 August 2013; Accepted 4 September 2013

Academic Editor: Giuseppe Calogero

Copyright (C) 2013 P. Phukan and D. Saikia. This is an open access article distributed under the Creative Commons Attribution License, which permits unrestricted use, distribution, and reproduction in any medium, provided the original work is properly cited.

CdSe quantum dots (QDs) dispersed in polyvinyl alcohol (PVA) matrix with their sizes within the quantum dot regime have been synthesized via a simple heat induced thermolysis technique. The effect of the concentrations of the cadmium source on the optical properties of CdSe/PVA thin films was investigated through UV-Vis absorption spectroscopy. The structural analysis and particle size determination as well as morphological studies of the CdSe/PVA nanocomposite thin films were done with the help of X-ray diffraction (XRD) and transmission electron microscopy (TEM). The XRD analysis reveals that CdSe/PVA nanocomposite thin film has a hexagonal (wurtzite) structure. A prototype thin film solar cell of CdSe/CdTe has been synthesized and its photovoltaic parameters were measured.

\section{Introduction}

Polymer nanocomposites are diverse and versatile functional materials in which nanoscale $(1-100 \mathrm{~nm})$ inorganic particles are dispersed in an organic polymer matrix to display enhanced optical, mechanical, magnetic, and optoelectronic properties [1-3]. The incorporation of semiconductor nanoparticles into polymer matrices is of great importance because of the potential applications of the resulting materials in wide variety of fields such as in fabrication of electronic devices [4-6], catalysis [7], gas sensors [8, 9], and nonlinear optics [10]. Bulk CdSe is a direct bandgap $(1.74 \mathrm{eV})$ II-VI semiconductor with an exciton Bohr radius of $6 \mathrm{~nm}[11,12]$. It exhibits either sphalerite cubic (zinc-blende type) or hexagonal (wurtzite type) structure. The hexagonal state is the stable phase while the sphalerite cubic is the metastable state [13]. From technological perspective, CdSe nanoparticles (NPs) are of significant interest because of their unique quantum confinement properties, bright photoluminescence, narrow emission band, and photostability [14]. CdSe-polymer nanocomposites find potential applications in the fabrication of devices like photovoltaic cells, laser, thin film transistors, light emitting diodes, and other nanoscale devices $[15,16]$. Many methods have been developed to synthesize CdSe in thin film form which includes chemical bath deposition (CBD) [17], vacuum evaporation [18], electrodeposition [19], spray pyrolysis [20], and successive ionic layer adsorption and reaction (SILAR) [21]. However, among these, CBD technique is preferable for the synthesis of polymer-capped CdSe nanocomposite thin film as it is easy to handle, cost effective, and suitable for large area deposition [22, 23].

In recent years, various works have focused on the synthesis and characterization of cadmium selenide (CdSe) QDs in polymeric matrices by wet chemical synthetic method [24-29]. Pecherska et al. successfully prepared CdSe QDs embedded in polymer matrix, and the effects of annealing temperature on the luminescent properties of the nanostructures were investigated [24]. PVA-capped CdSe NPs were synthesized by Shah et al. via a simple chemical route and studied the influence of precursor concentration, aging time, and reaction temperature on the size of the as-synthesized CdSe NPs as well as on their optical properties [25]. Photoluminescence properties of CdSe-PVA nanocomposites with small and narrow size distribution obtained by varying the polymer concentrations were reported by Kushwaha et al. [26]. Ma et al. reported the room temperature synthesis of CdSe nanoparticles dispersed in PVA matrix via one-step solution growth technique and studied their optical and 
structural properties [27]. Suo et al. fabricated the poly (vinyl alcohol) nanocomposite thin film reinforced with CdSeZnS quantum dots by drop casting method and investigated their optical properties [28]. Mansur et al. reported the synthesis and characterization of CdSe nanoparticles using acid-functionalized PVA as capping ligands via aqueous route at room temperature by methods of colloidal chemistry [29].

The aim of the present study is to synthesize CdSe/PVA nanocomposite thin films tuned with hexagonal phase by heat induced thermolysis technique and also to study the effect of concentrations of cadmium ion on its optical properties. The optimised CdSe/PVA nanocomposite thin film will be utilised for fabrication and evaluation of a prototype $\mathrm{CdSe} / \mathrm{CdTe}$ solar cell.

\section{Experimental}

2.1. Materials and Characterizing Techniques. All reagents such as sodium sulphite $\left(\mathrm{Na}_{2} \mathrm{SO}_{3}\right)$, metallic selenium powder, cadmium chloride $\left(\mathrm{CdCl}_{2} \cdot \mathrm{H}_{2} \mathrm{O}\right)$, and polyvinyl alcohol were purchased from Merk (India) Ltd. and used directly as received without any further purification. Deionised water was used throughout the experimental work.

The structural properties of the CdSe/PVA thin films were analysed with a Rigaku Ultima-IV X-ray diffractometer using $\mathrm{CuK} \alpha$ radiations operated at $40 \mathrm{kV}$ and $40 \mathrm{~mA}$. For optical studies, absorption spectra were recorded with a Scinco (S 3100) PD UV-Vis spectrophotometer. The high resolution transmission electron microscopy (HRTEM) images were taken by a TECNAI-T 30 model instrument operated at an accelerating voltage of $300 \mathrm{kV}$. The photovoltaic parameters of the cell were measured by Keithley-2400 source meter under illumination with a $100 \mathrm{~mW} \mathrm{~cm}^{-2}$ (1 SUN) xenon lamp.

2.2. Synthesis of CdSe/PVA Nanocomposite. The CdSe/PVA nanocomposite thin films were deposited on chemically clean glass substrate by reacting $\mathrm{Cd}^{2+}$ dispersed PVA with sodium selenosulphite via heat induced thermolysis technique. The synthesis technique is derived from Saikia et al. [30] for CdS/PVA nanocomposite thin film. At first, $1 \mathrm{M}$ sodium selenosulphite $\left(\mathrm{Na}_{2} \mathrm{SeSO}_{3}\right)$ solution was prepared by adding $0.05 \mathrm{~mol}$ of powdered selenium into $100 \mathrm{~mL}$ of $1 \mathrm{M}$ sodium sulphite $\left(\mathrm{Na}_{2} \mathrm{SO}_{3}\right)$ solution. The resultant mixture was refluxed at $70^{\circ} \mathrm{C}$ for $3 \mathrm{hr}$ with constant stirring. After refluxing, the final solution was filtered with a Whatman filter paper and was stored in the dark at $(60 \pm 5)^{\circ} \mathrm{C}$ to prevent decomposition against its instability at room temperature.

In a typical reaction, a matrix solution was prepared by adding $1 \mathrm{~mL}$ of $0.01 \mathrm{M}$ cadmium chloride into $20 \mathrm{~mL}$ of $5 \%(\mathrm{~W} / \mathrm{V})$ aqueous solution of PVA and stirred continuously for 15-20 minutes. $1 \mathrm{~mL}$ of diluted sodium selenosulphite $(0.1 \mathrm{M})$ was added drop by drop into this matrix solution, and the reactants were stirred continuously for another 15 minutes. On stirring, the resulting precursor solution becomes transparent, and gradually the colour changes to orange. The final solution containing $\mathrm{Cd}^{2+}$ and $\mathrm{Se}^{2-}$ ions in the polymeric matrix was coated onto chemically clean glass substrate by dip coating technique and then subjected to thermolysis at $300^{\circ} \mathrm{C}$. The colour of the film changes from transparent to brown within 15-20 minutes indicating the formation of CdSe nanocrystals in the PVA matrix. A set of five samples were prepared for various concentrations of $\mathrm{CdCl}_{2}(0.01 \mathrm{M}, 0.05 \mathrm{M}, 0.1 \mathrm{M}, 0.6 \mathrm{M}$, and $1.1 \mathrm{M})$ and a fixed concentration of $\mathrm{Na}_{2} \mathrm{SeSO}_{3}(0.1 \mathrm{M})$. Further, the films were annealed at $100^{\circ} \mathrm{C}$ for 6 hours. The samples were labelled as S1, $\mathrm{S} 2, \mathrm{~S} 3, \mathrm{~S} 4$, and $\mathrm{S} 5$ for $\mathrm{CdCl}_{2}$ concentrations of $0.01 \mathrm{M}, 0.05 \mathrm{M}$, $0.1 \mathrm{M}, 0.6 \mathrm{M}$, and $1.1 \mathrm{M}$, respectively.

2.3. Fabrication of the Cell. A thin film solar cell with the structure Glass/ITO/CdSe/CdTe/Al has been fabricated in which CdSe layer was deposited on top of the ITO coated glass substrate by heat induced thermolysis technique at $300^{\circ} \mathrm{C}$ as described above. Prior to the deposition of $\mathrm{CdTe}$ thin film, the $\mathrm{CdSe}$ thin film was annealed at $100^{\circ} \mathrm{C}$ for 6 hours. Then, a layer of CdTe was deposited on the top of the CdSe layer by the thermal evaporation method at a pressure of $10^{-6}$ mbar. Finally, a layer of $\mathrm{Al}$ was deposited on the top as a back contact by the thermal evaporation method. The final cell structure is shown in Figure 4(a), and the device had an area of $1 \times 1 \mathrm{~cm}^{2}$.

\section{Results and Discussions}

3.1. Optical Studies. The UV-Vis absorption spectra of the CdSe/PVA nanocomposite thin films (S1, S2, S3, S4, and S5) are shown in Figure 1(a). The absorbance in the spectra is found to increase gradually as the concentration of $\mathrm{CdCl}_{2}$ is increased from $0.01 \mathrm{M}$ to $1.1 \mathrm{M}$. It is observed that at a lower concentration of $\mathrm{CdCl}_{2}(\mathrm{~S} 1, \mathrm{~S} 2)$, the $\mathrm{CdSe} / \mathrm{PVA}$ thin films exhibited low absorbance, and no absorption peak was found, while those deposited at higher concentration of $\mathrm{CdCl}_{2}(\mathrm{~S} 3$, S4, S5) exhibited high absorbance and prominent peaks were observed (in the range of $560 \mathrm{~nm}-660 \mathrm{~nm}$ ). The absorption edges in the CdSe thin films ( $\mathrm{S} 1$ to $\mathrm{S} 4$ ) are found to be blue-shifted relative to the bulk CdSe band edge of $713 \mathrm{~nm}$ $[25,29]$, whereas the absorption edge in case of sample S5 is red-shifted. The blue shift in the absorption edges may be attributed due to the quantum confinement effect in CdSe nanoparticles [25, 31]. From the spectra, it is observed that the sharp increase in absorbance near the fundamental absorption edge for the CdSe/PVA thin films (S4 and S5) is an indication of good crystalline nature of the films [32]. The red shift in the spectra (S5) indicates the formation of nanoparticles greater than the exciton Bohr radius (EBR) of CdSe $[25,31]$.

The optical bandgaps of the films were obtained using the following equation [33] for a semiconductor:

$$
A=\frac{k(h v-E g)^{m / 2}}{h \nu},
$$

where $A$ is the absorbance, $K$ a constant, and $m$ equal to 1 for direct transition and 2 for indirect transition. Linearity of the plots of $(A h \nu)^{2}$ versus photon energy $h v$ for the CdSe/PVA films indicates that the material is of direct bandgap nature.

The extrapolation of the straight line to the $(A h \nu)^{2}=$ 0 axis (Figure 1(b)) gives the energy bandgap of the film 


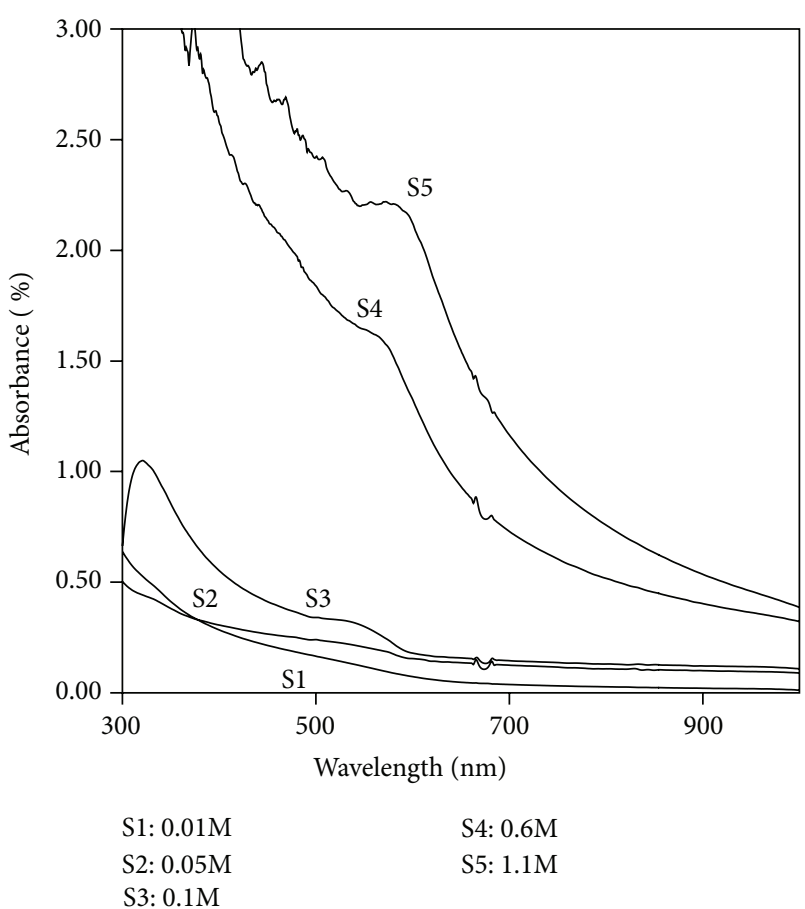

(a)

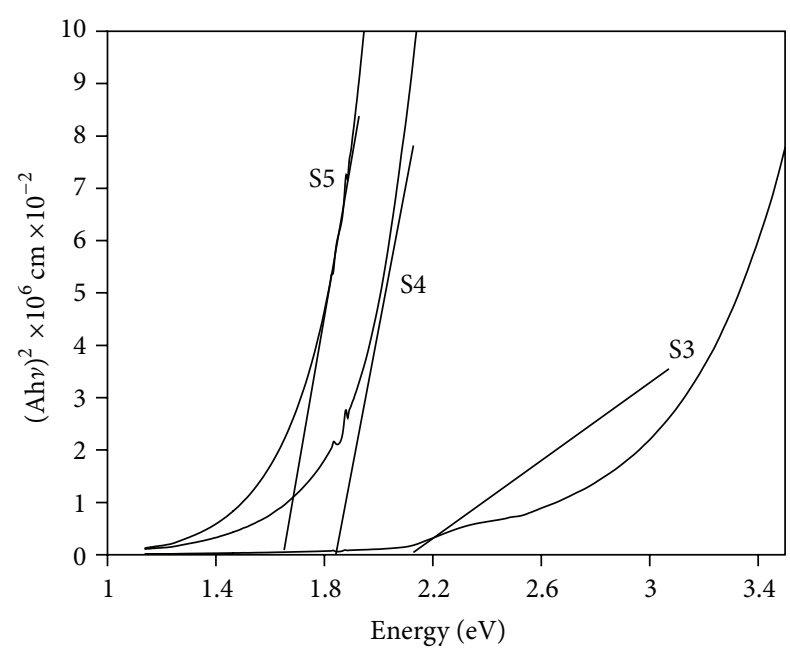

S3: $0.1 \mathrm{M}$

S4: $0.1 \mathrm{M}$

S5: $0.1 \mathrm{M}$

(b)

FIgURE 1: (a) UV-Vis absorption spectra of CdSe/PVA nanocomposite thin films (S1, S2, S3, S4, and S5) prepared by thermolysis at $300^{\circ} \mathrm{C}$. (b) Bandgap calculation of CdSe/PVA nanocomposite thin films (S3, S4, and S5) prepared by thermolysis at $300^{\circ} \mathrm{C}$.

material (S3, S4, and S5). The bandgaps of the films S3 and $\mathrm{S} 4$ were found to be $2.1 \mathrm{eV}$ and $1.8 \mathrm{eV}$, respectively, which is higher than that of the bulk CdSe bandgap of $1.74 \mathrm{eV}$. But the bandgap of the film S5 is found to be $1.6 \mathrm{eV}$ which is smaller than the bulk bandgap of CdSe and as such is not preferable for application in solar cell. The increase in the

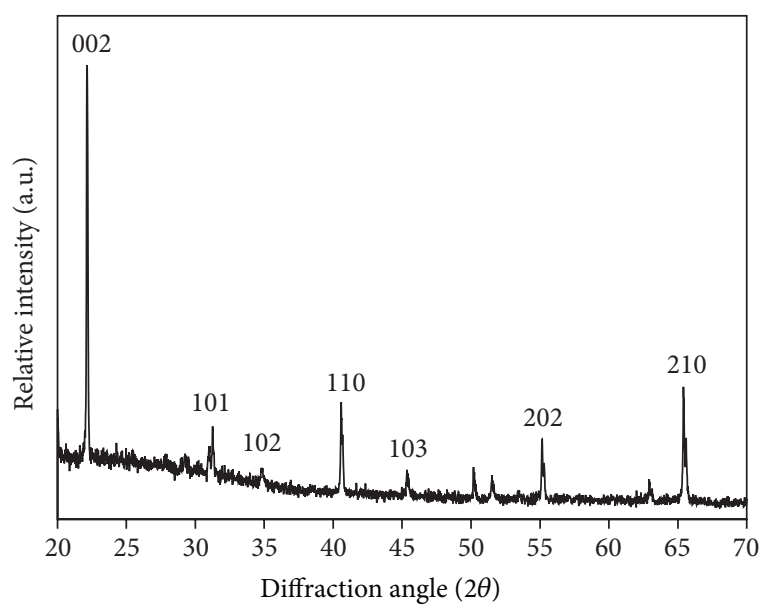

FIgURE 2: XRD of CdSe thin film (S4) prepared by thermolysis at $300^{\circ} \mathrm{C}$.

TABLE 1: Bandgap, shift in bandgap, and particle size calculated from absorption spectra.

\begin{tabular}{lccc}
\hline Sample & $\begin{array}{c}\text { Bandgap from } \\
\text { UV-Vis }(\mathrm{eV})\end{array}$ & $\begin{array}{c}\text { Shift in } \\
\text { bandgap }(\mathrm{eV})\end{array}$ & $\begin{array}{c}\text { Particle size } \\
\text { from EMA (nm) }\end{array}$ \\
\hline S3 & 2.1 & 0.36 & 4.5 \\
S4 & 1.8 & 0.06 & 11.1 \\
\hline
\end{tabular}

bandgap is due to the formation of small size CdSe NPs. From the bandgap information, the size of the CdSe nanoparticles for the samples S3 and S4 was calculated using effective mass approximation (EMA) method [31] and the following equation for a semiconductor:

$$
E_{\mathrm{gn}}-E_{\mathrm{gb}}=\frac{\left(\hbar^{2} \pi^{2} / 2 R^{2}\right)}{\mu},
$$

where $\mu$ is the effective mass of the specimen $\left[1 / \mu=1 / m_{e}{ }^{*}+\right.$ $\left.1 / m_{h}{ }^{*}\right], m_{e}{ }^{*}$ is the effective mass of electron $\left(0.13 m_{e}\right), m_{h}{ }^{*}$ is the effective mass of hole $\left(0.45 m_{e}\right), R$ is the radius of the particle, $E_{\mathrm{gb}}$ is the bulk bandgap, and $E_{\mathrm{gn}}$ is the bandgap of the sample. The observations are shown in Table 1.

From the above discussion, it is found that the film S4 is preferable for application as window layer in solar cell due to its suitable bandgap and high absorbance in the visible range.

3.2. XRD Analysis. A typical X-ray diffraction pattern of CdSe/PVA nanocomposite thin film (sample S4) is shown in Figure 2. The XRD pattern shows several peaks at $2 \theta$ values of $22.1^{\circ}, 31.1^{\circ}, 35^{\circ}, 40.5^{\circ}, 45.36^{\circ}, 55.1^{\circ}$, and $65.4^{\circ}$ which may be assigned to the diffraction lines produced by the (002), (101), (102), (110), (103), (202), and (210) planes of hexagonal (wurtzite) structure of CdSe, respectively [14, 34]. The appearance of the (102) and (103) reflection planes at diffraction angles $2 \theta=35.1^{\circ}$ and $45.36^{\circ}$ is an indication of the hexagonal (wurtzite) structure of CdSe thin film [35]. The appearance of many peaks in the XRD pattern is an indication of polycrystalline nature of the CdSe thin film. The crystallite 


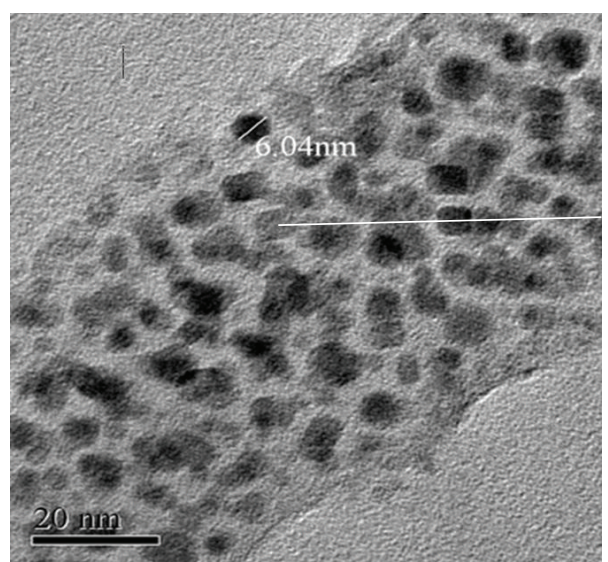

(a)

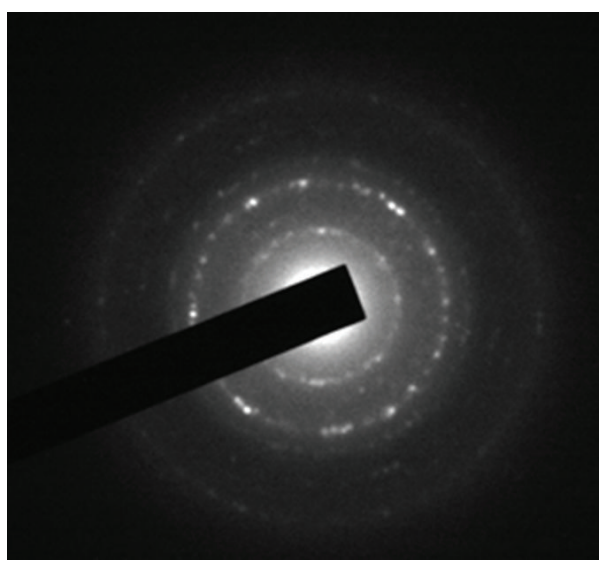

(c)

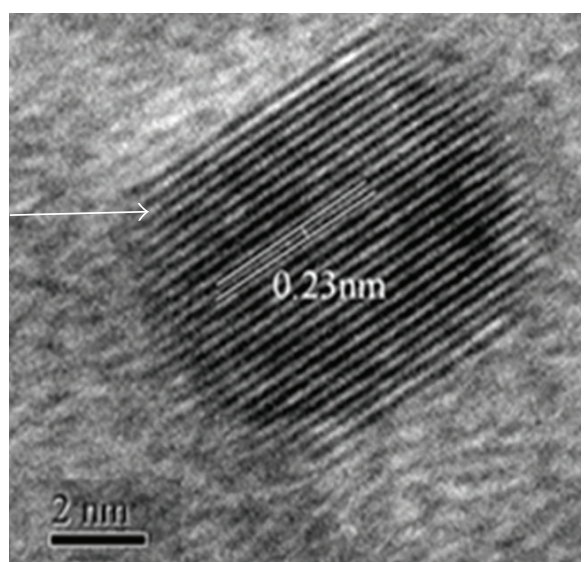

(b)

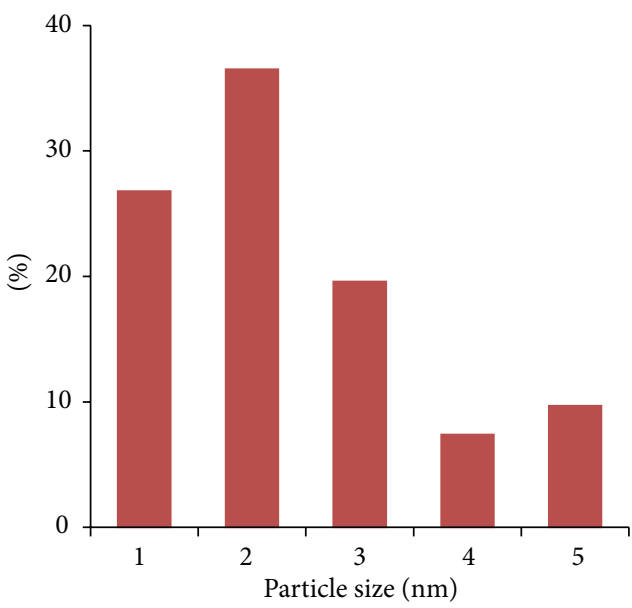

(d)

FIgURE 3: (a) TEM image of CdSe thin film (S4) prepared by thermolysis at $300^{\circ} \mathrm{C}$. (b) HRTEM image of CdSe thin film (S4) prepared by thermolysis at $300^{\circ} \mathrm{C}$. (c) SAED image of CdSe thin film (S4) prepared by thermolysis at $300^{\circ} \mathrm{C}$. (d) Size distribution of CdSe nanoparticles.

size in CdSe thin film is evaluated from the intensity peaks of XRD by a Gaussian fit, using Debye-Scherrer formula:

$$
D=\frac{0.9 \lambda}{\beta \cos \theta}
$$

where $\beta$ is the full width at half maximum, $\lambda$ is the wavelength for X-ray used, and $\theta$ is Bragg's angle.

3.3. TEM Analysis. The TEM micrograph of CdSe/PVA nanocomposite thin film (S4) prepared at $300^{\circ} \mathrm{C}$ is presented in Figure 3(a). From the micrograph, it is observed that CdSe NPs has uniform size distribution with an average size of $4-5 \mathrm{~nm}$ in diameter, almost spherical in shape and are well dispersed within the pores of PVA matrix. The HRTEM image of CdSe NPs (S4) is depicted in Figure 3(b). The image shows the lattice fringes in the as-synthesized CdSe/PVA thin film and the spacing between the lattice fringes was found to be $0.23 \mathrm{~nm}$ which is very close to the $d$ value of $0.22 \mathrm{~nm}$ (Table 2) for (110) reflection plane in the XRD spectrum. The selected area electron diffraction (SAED) pattern of the CdSe/PVA thin film prepared at $300^{\circ} \mathrm{C}$ is shown in Figure 3(c). The SAED pattern indicates the hexagonal phase of the as-synthesized CdSe NPs. The analysis of particle size distribution is done with the help of histogram and is presented in Figure 3(d). The size histogram of CdSe nanoparticles is constructed by counting the total numbers of particles spread on the region of TEM grid as shown in Figure 3(a). Out of 41 numbers of total calculated particles, highest population is obtained in the $4-6 \mathrm{~nm}$ size range. From the analysis, it is found that as-synthesized CdSe nanoparticles exhibit an average size of about $4-6 \mathrm{~nm}$ in diameter. A comparative study of the average grain size of CdSe NPs obtained by TEM, EMA, and XRD measurements is presented in Table 3 .

\section{Characterization of the Cell}

The current-voltage $(I-V)$ characteristic of the CdSe/CdTe solar cell was measured with a Keithley (M: 2400) source meter under one sun illumination intensity and is shown in Figure 4(b). The photovoltaic parameters are tabulated in Table 4 . A conversion efficiency of $2.43 \%$ has been obtained for the cell. 


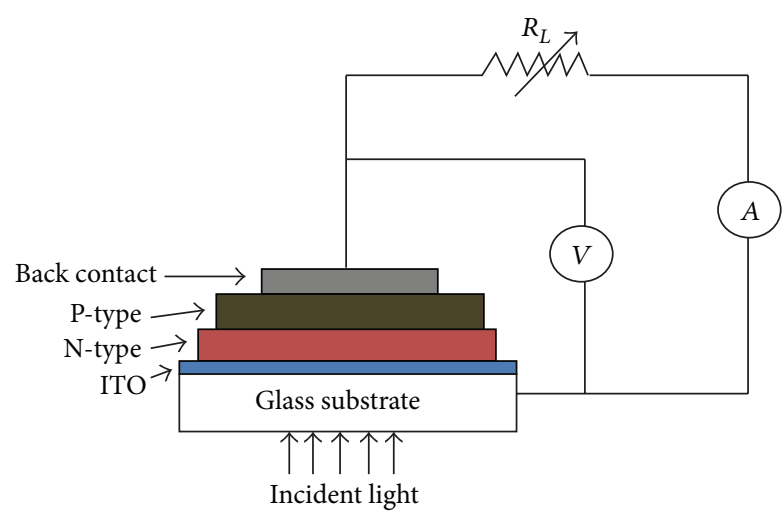

(a)

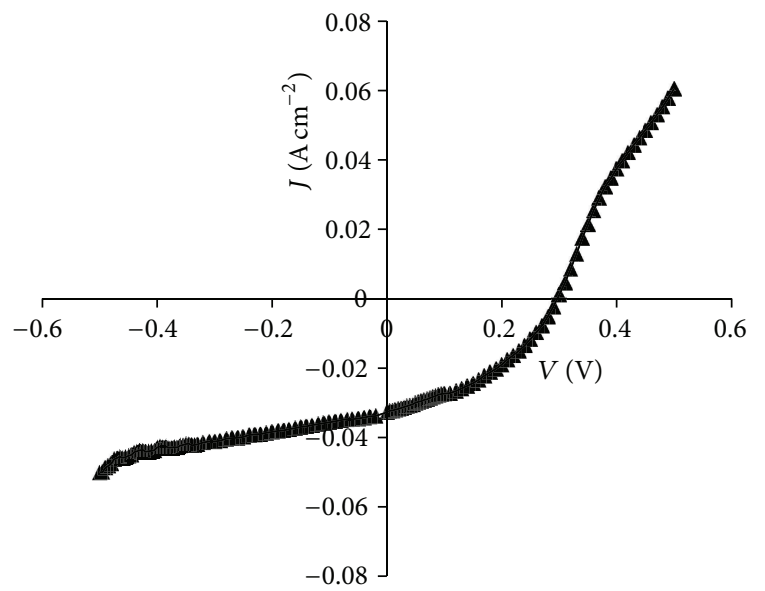

(b)

Figure 4: (a) Experimental setup for measuring the currentvoltage characteristics of CdSe/CdTe thin film solar cell and (b) $I-V$ characteristics of CdSe/CdTe thin film solar cell.

TABLE 2: Grain size and structural parameters of CdSe thin film from XRD.

\begin{tabular}{lccccc}
\hline Sample & $\begin{array}{c}2 \theta \\
(\text { degree })\end{array}$ & $\begin{array}{c}\text { Reflection } \\
\text { planes (hkl) }\end{array}$ & $\begin{array}{c}d \text { value } \\
(\AA ̊)\end{array}$ & $\begin{array}{c}\text { Grain size } \\
(\mathrm{nm})\end{array}$ & $\begin{array}{c}\text { Average } \\
\text { grain size } \\
(\mathrm{nm})\end{array}$ \\
\hline \multirow{4}{*}{$\mathrm{S} 4$} & 22.1 & 002 & 4.0117 & 13.3 & \\
& 31.1 & 101 & 3.0299 & 7 & \\
& 35 & 102 & 2.8077 & 10.93 & \\
& 40.5 & 110 & 2.2213 & 13.6 & 10.69 \\
& 45.36 & 103 & 1.9977 & 8.45 & \\
& 55.1 & 202 & 1.6643 & 9.3 & \\
& 65.4 & 210 & 1.4254 & 12.2 & \\
\hline
\end{tabular}

\section{Conclusion}

CdSe quantum dots of average size of $4-6 \mathrm{~nm}$ in diameter dispersed in PVA matrix have been synthesized in thin film form by heat induced thermolysis technique. The XRD analysis indicated the hexagonal (wurtzite) structure of CdSe/PVA nanocomposite thin film. The optical studies reveal that CdSe/PVA nanocomposite thin film prepared from $0.6 \mathrm{M}$
TABLE 3: Average grain size obtained from XRD, EMA, and TEM analysis.

\begin{tabular}{lcccc}
\hline Sample & $\begin{array}{c}\text { Growth } \\
\text { temperature }\end{array}$ & $\begin{array}{c}\text { Particle size } \\
\text { from XRD } \\
(\mathrm{nm})\end{array}$ & $\begin{array}{c}\text { Particle size } \\
\text { from EMA } \\
(\mathrm{nm})\end{array}$ & $\begin{array}{c}\text { Particle size } \\
\text { from TEM } \\
(\mathrm{nm})\end{array}$ \\
\hline $\mathrm{S} 4$ & $300^{\circ} \mathrm{C}$ & 10.69 & 11.1 & 5 \\
\hline
\end{tabular}

TABLE 4: Photovoltaic parameters for the CdSe/CdTe thin film solar cell under $100 \mathrm{~mW} \mathrm{~cm}^{-2}$ illumination intensity.

\begin{tabular}{lccccc}
\hline Solar cell & $I\left(\mathrm{~mW} \mathrm{~cm}^{-2}\right)$ & $V_{\mathrm{oc}}(\mathrm{mV})$ & $J_{\mathrm{sc}}\left(\mathrm{mA} / \mathrm{cm}^{2}\right)$ & $\mathrm{FF}(\%)$ & $\eta(\%)$ \\
\hline $\mathrm{CdSe} / \mathrm{CdTe}$ & 100 & 290 & 33 & 25.3 & 2.43
\end{tabular}

$I, V_{\mathrm{oc}}, J_{\mathrm{sc}}, \mathrm{FF}$, and $\eta$ represent illumination intensity, open circuit voltage, short circuit current density, fill factor, and efficiency, respectively.

concentration of $\mathrm{CdCl}_{2}$ (S4) is found to be suitable for application as a window layer in fabrication of solar cell. The efficiency of the as-fabricated $\mathrm{CdSe} / \mathrm{CdTe}$ solar cell was found to be $2.43 \%$.

\section{Acknowledgments}

One of the authors D. Saikia acknowledges the financial support from the Department of Electronics and Information Technology (DeitY), R\&D Electronics Group, Government of India, New Delhi, India, under a major research project to Sibsagar College, Joysagar, Assam, India.

\section{References}

[1] R. Shenhar, T. B. Norsten, and V. M. Rotello, "Polymer-mediated nanoparticle assembly: structural control and applications," Advanced Materials, vol. 17, no. 6, pp. 657-669, 2005.

[2] D. R. Paul and L. M. Robeson, "Polymer nanotechnology: nanocomposites," Polymer, vol. 49, no. 15, pp. 3187-3204, 2008.

[3] A. Lagashetty and A. Venkataraman, "Polymer nanocomposites," Resonance, vol. 10, no. 7, pp. 49-60, 2005.

[4] O. M. Folarin, E. R. Sadiku, and A. Maity, "Polymer-noble metal nanocomposites: review," International Journal of Physical Sciences, vol. 6, no. 21, pp. 4869-4882, 2011.

[5] I. S. Liu, H. H. Lo, C. T. Chien et al., "Enhancing photoluminescence quenching and photoelectric properties of CdSe quantum dots with hole accepting ligands," Journal of Materials Chemistry, vol. 18, pp. 675-682, 2008.

[6] Y. J. Lai, Y. C. Lin, C. P. Fu et al., "Growth mode transfer of self-assembled CdSe quantum dots grown by molecular beam epitaxy," Journal of Crystal Growth, vol. 286, no. 2, pp. 338-344, 2006.

[7] S. H. Liu, X. F. Qian, J. Yin, H. A. Xi, Z. H. Huang, and Z. K. $\mathrm{Zhu}$, "Fabrication of CdS nanocrystals embedded in copolymer matrix by an in situ simultaneous copolymerization-sulfidation technique," Materials Science and Engineering B, vol. 98, no. 2, pp. 99-103, 2003.

[8] H. Zan, C. Li, C. Yeh, M. Dai, H. Meng, and C. Tsai, "Roomtemperature-operated sensitive hybrid gas sensor based on amorphous indium gallium zinc oxide thin-film transistors," Applied Physics Letters, vol. 98, no. 25, Article ID 253503, 3 pages, 2011. 
[9] R. A. Potyrailo and A. M. Leach, "Selective gas nanosensors with multisize CdSe nanocrystal/polymer composite films and dynamic pattern recognition," Applied Physics Letters, vol. 88, no. 13, Article ID 134110, 2006.

[10] X. Liu, Y. Adachi, Y. Tomita, J. Oshima, T. Nakashima, and T. Kawai, "High-order nonlinear optical response of a polymer nanocomposite film incorporating semiconducotor CdSe quantum dots," Optics Express, vol. 20, no. 12, pp. 13457-13469, 2012.

[11] C. Baban, G. I. Rusu, and P. Prepelita, "On the optical properties of polycrystalline CdSe thin films," Journal of Optoelectronics and Advanced Materials, vol. 7, no. 2, pp. 817-821, 2005.

[12] R. Blargava, Properties of Wide Band Gap II-VI Semiconductors, INSPEC, London, UK, 1997.

[13] P. U. Asogwa, "Optical and structural properties of chemical bath deposited CdSe nanoparticle thin films for photovoltaic applications," Journal of Non-Oxide Glasses, vol. 2, no. 4, pp. 183$189,2010$.

[14] P. Srivastava and K. Singh, "Synthesis of CdSe nanoparticles by solvothermal route: structural, optical and spectroscopic properties," Advanced Materials Letters, vol. 3, no. 4, pp. 340344, 2012.

[15] D. Yu, B. L. Wehrenberg, P. Jha, J. Ma, and P. Guyot-Sionnest, "Electronic transport of n-type CdSe quantum dot films: effect of film treatment," Journal of Applied Physics, vol. 99, no. 10, Article ID 104315, 2006.

[16] D. C. Oertel and M. G. Bawendi, "Photodetectors based on treated CdSe quantum-dot films," Applied Physics Letters, vol. 87, Article ID 213505, 2005.

[17] S. Erat, H. Metin, and M. Ari, "Influence of the annealing in nitrogen atmosphere on the XRD, EDX, SEM and electrical properties of chemical bath deposited CdSe thin films," Materials Chemistry and Physics, vol. 111, no. 1, pp. 114-120, 2008.

[18] C. Baban and G. I. Rusu, "On the structural and optical characteristics of CdSe thin films," Applied Surface Science, vol. 211, no. 1-4, pp. 6-12, 2003.

[19] A. Acharya, R. Mishra, and G. S. Roy, "Characterization of CdSe/Polythiophene nanocomposite by TGA/DTA, XRD, UVVIS Spectroscopy, SEM-EDXA and FTIR," Armenian Journal of Physics, vol. 3, no. 3, pp. 195-202, 2010.

[20] M. M. Betkar and G. D. Bagde, "Structural and optical properties of spray deposited CdSe Thin films," Materials Physics and Mechanics, vol. 14, pp. 74-77, 2012.

[21] B. Guzeldir, M. Saglam, and A. Ates, "Preparation and characterization of CdSe, $\mathrm{ZnSe}$ and CuSe thin films deposited by the successive ionic layer adsorption and reaction method," Journal of Optoelectronics and Advanced Materials, vol. 14, no. 3-4, pp. 224-229, 2012.

[22] A. M. Salem, "Structure, refractive-index dispersion and the optical absorption edge of chemically deposited $\operatorname{ZnxCd}(1-\mathrm{x}) \mathrm{S}$ thin films structure, refractive-index dispersion and the optical absorption edge of chemically deposited $\mathrm{ZnxCd}(1-\mathrm{x}) \mathrm{S}$ thin films," Applied Physics A, vol. 74, no. 2, pp. 205-211, 2002.

[23] J. McAleese and P. O’Brien, "Developing an understanding of the processes controlling the chemical bath deposition of $\mathrm{ZnS}$ and CdS," Journal of Materials Chemistry, vol. 8, pp. 2309-2314, 1998.

[24] K. Y. Pechers'ka, L. P. Germash, N. O. Korsunska et al., "Effect of annealing on the luminescent characteristics of CdSe quantum dots in a polymer," Ukrainian Journal of Physics, vol. 55, no. 4 , pp. 403-409, 2010.
[25] C. P. Shah, M. Rath, M. Kumar, and P. N. Bajaj, "Precursor concentration and temperature controlled formation of polyvinyl alcohol-capped CdSe-quantum dots," Beilstein Journal of Nanotechnology, vol. 1, pp. 119-127, 2010.

[26] K. Kushwaha, N. Gautam, P. Singh, and M. Ramrakhaini, "Synthesis and photoluminescence of CdSe/PVA nanocomposites," Journal of Physics, vol. 365, Article ID 012014, 2012.

[27] X.-D. Ma, X.-F. Qian, J. Yin, H.-A. Xi, and Z.-K. Zhu, "Preparation and characterization of polyvinyl alcohol-capped CdSe nanoparticles at room temperature," Journal of Colloid and Interface Science, vol. 252, no. 1, pp. 77-81, 2002.

[28] B. Suo, X. Su, J. Wu, D. Chen, A. Wang, and Z. Guo, "Poly (vinyl alcohol) thin film filled with CdSe-ZnS quantum dots: fabrication, characterization and optical properties," Materials Chemistry and Physics, vol. 119, no. 1-2, pp. 237-242, 2010.

[29] H. S. Mansur and A. A. P. Mansur, "CdSe quantum dots stabilized by carboxylic-functionalized PVA: synthesis and UVvis spectroscopy characterization," Materials Chemistry and Physics, vol. 125, no. 3, pp. 709-717, 2011.

[30] D. Saikia, P. K. Saikia, P. K. Gogoi, M. R. Das, P. Sengupta, and M. V. Shelke, "Synthesis and characterization of CdS/PVA nanocomposite thin films from a complexing agent free system," Materials Chemistry and Physics, vol. 131, no. 1-2, pp. 223-229, 2011.

[31] L. E. Brus, "Electron-electron and electron hole interactions in small semiconductor crystallites: the size dependence of the lowest excited electronic state," Journal of Chemical Physics, vol. 80, no. 9, article 4403, 7 pages, 1984.

[32] D. Saikia, P. K. Gogoi, P. K. Saikia, and S. Sarma, "Synthesis of polymer-PbS nanocomposite by solar irradiation-induced thermolysis process and its photovoltaic applications," Journal of Experimental Nanoscience, vol. 8, no. 3, pp. 403-411, 2013.

[33] B. Subramanian, C. Sanjeevviraja, and M. Jayachandran, "Brush plating of tin(II) selenide thin films," Journal of Crystal Growth, vol. 234, no. 2-3, pp. 421-426, 2002.

[34] G. Ramalingam and J. Madhavan, "Investigation on the structural and morphological behaviour of CdSe nanoparticles by hydrothermal method," Archives of Applied Science Research, vol. 3, no. 3, pp. 217-224, 2011.

[35] Z. Deng, L. Cao, F. Tang, and B. Zou, "A new route to zincblende CdSe nanocrystals: mechanism and synthesis," Journal of Physical Chemistry B, vol. 109, no. 35, pp. 16671-16675, 2005. 

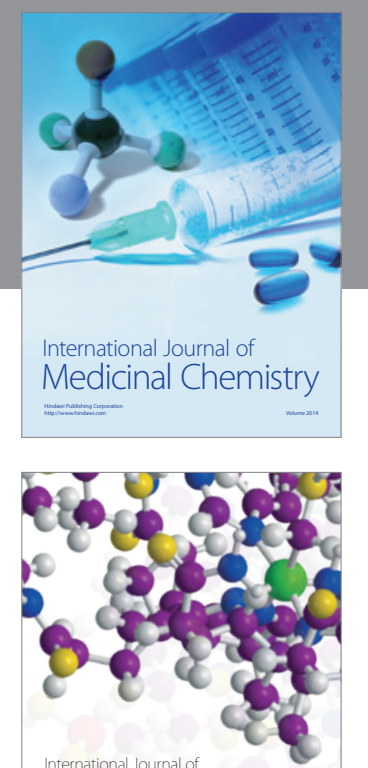

\section{Carbohydrate} Chemistry

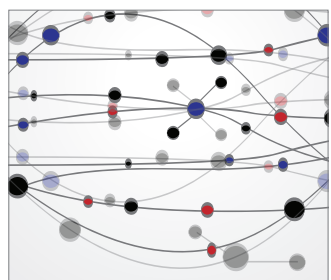

The Scientific World Journal
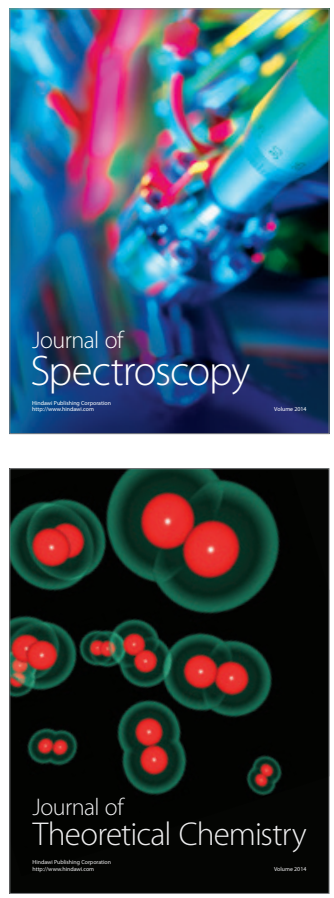
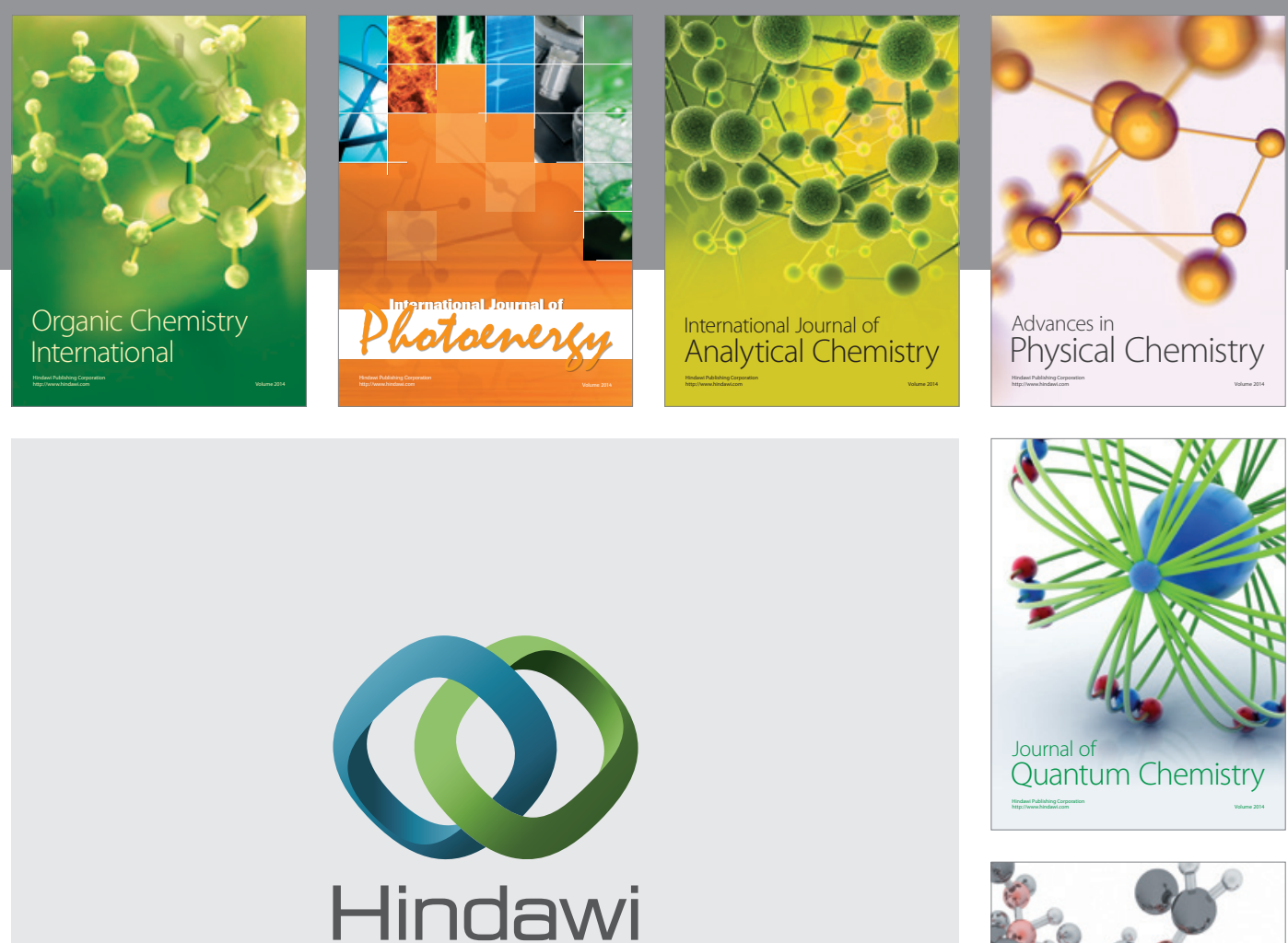

Submit your manuscripts at

http://www.hindawi.com

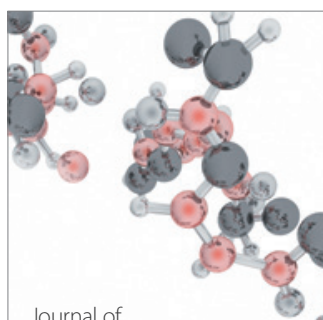

Analytical Methods

in Chemistry

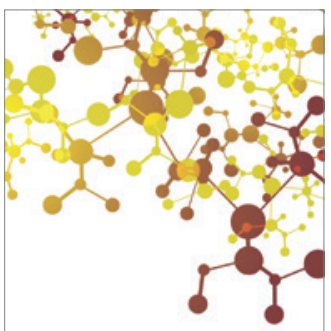

Journal of

Applied Chemistry

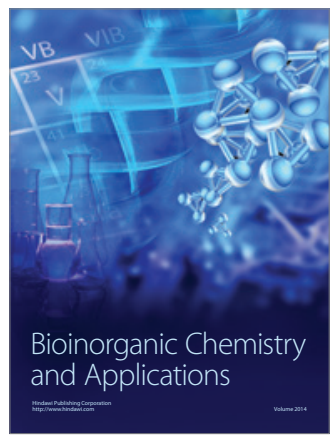

Inorganic Chemistry
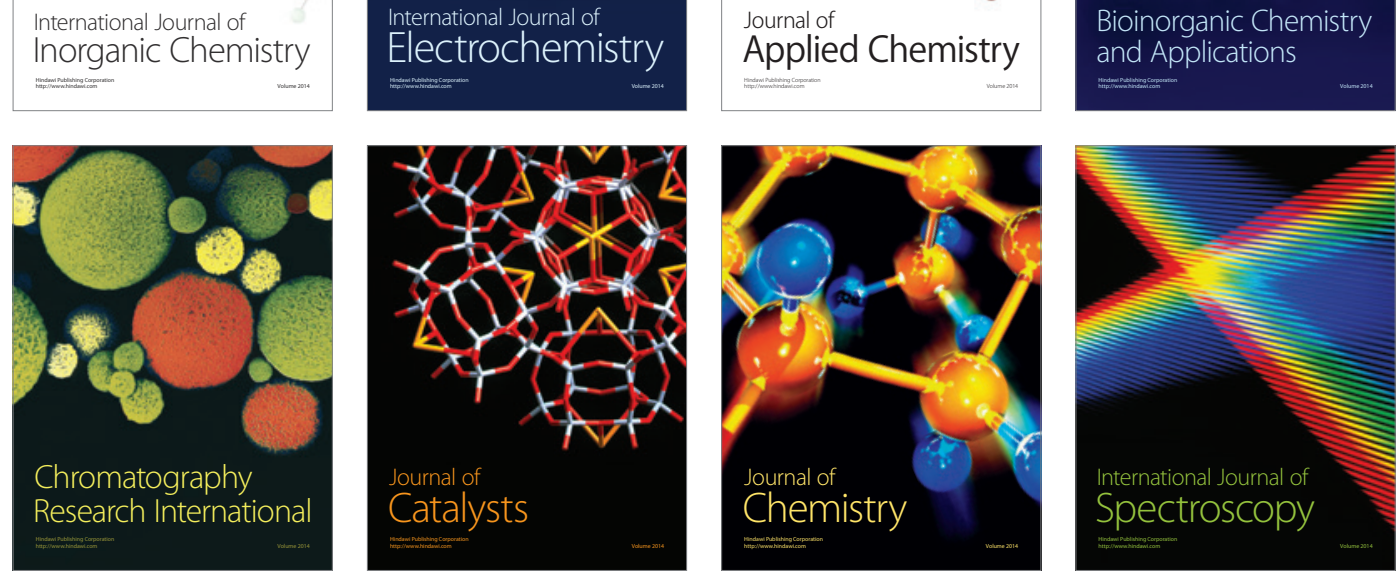